Ann. Parasitol. Hum. Comp., 1990, $65: \mathrm{n}^{\circ}$ 5-6, 262-266.

Mémoire.
Key-words: Tick. Ixodes ricinus. Rabbit. Immunity. Cyclosporin A. Immunosuppression.

Mots-clés : Tique. Ixodes ricinus. Immunité. Lapin. Cyclosporin A. Immunosuppression.

\title{
RABBITS INFESTED WITH IXODES RICINUS L. ADULTS: EFFECTS OF A TREATMENT WITH CYCLOSPORIN A ON THE BIOLOGY OF TICKS FED ON NAIVE AND IMMUNE HOSTS
}

\author{
P. GIRARDIN, M. BROSSARD
}

\begin{abstract}
SUMMARY
Rabbits have been infested 3 times with 10 female and 10 male Ixodes ricinus. Immunity which is induced when ticks feed on naive animals (1st infestation) perturbs feeding, oviposition and embryogenesis during reinfestations. Treatment of rabbits during a 3rd infestation (resistant animals) with cyclosporin A (CsA), an immunosuppressive agent which works on the cellular compartment (chiefly $\mathrm{T}$ helper cells), partially reversed the negative effects
\end{abstract}

of the immunity on the biology of the ticks.

Conversely, CsA may also directly affect the reproductive processes of ticks. Thus, the weight of the eggs laid and the egg conversion factor of ticks fed on naive treated hosts (1st infestation) were diminished. In addition, the preoviposition was prolonged, and finally failure in oviposition and hatching occured more frequently.

RÉsumé : Infestations de lapins par les adultes d'Ixodes ricinus $\mathbf{L}$. : effet d'un traitement par la cyclosporine A sur la biologie des tiques nourries sur des hôtes indemnes ou immuns.

L'intervention du compartiment cellulaire dans l'immunité de lapins contre les tiques Ixodes ricinus a été montrée en traitant les animaux par la cyclosporine A (CsA), un immunosuppresseur agissant essentiellement sur les cellules $\mathrm{T}$ auxiliaires.

Des lapins ont été infestés à 3 reprises par 10 femelles et 10 mâles d'I. ricinus. L'immunité induite durant la première infestation perturbe la nutrition, l'oviposition et l'embryogenèse des tiques lors de réinfestations. Le traitement des animaux par la CsA au cours d'une $3^{\mathrm{e}}$ infestation inhibe ces effets défavorables.

D'autre part, la CsA affecte directement le processus de reproduction. En effet, les pontes des tiques de première infestation, nourries sur des lapins traités, sont moins abondantes. La préoviposition est aussi prolongée, alors que l'oviposition et l'éclosion des œufs échouent plus fréquemment.

\section{INTRODUCTION}

The immune response of rabbits to adult $I$. ricinus bites has been characterized (Bowessidjaou et al., 1977; Brossard, 1977; Brossard et al., 1982; Brossard, Girardin, 1979; Brossard, Fivaz, 1982; Girardin, Brossard, 1985; Girardin, Brossard, 1989). This response leads to a state of resistance against the ticks after repeated infestations (Bowessidjaou et al., 1977; Brossard et al., 1982). Thus, the average duration of the bloodmeal, preoviposition and embryogenesis are prolonged and engorgement, egg laying frequency, egg conversion factor (weight of eggs laid/weight of fed female), as well as hatching frequency are diminished.

Cyclosporin A (CsA), an immunosuppressive agent largely applied in transplantation surgery, inhibits rejection of allografts (Borel, 1981; Britton, Palacios, 1982), as well

Institut de Zoologie, Université de Neuchâtel, Chantemerle 22, CH-2007 Neuchâtel.

Accepté le : 29 octobre 1990. as graft versus host reactions (Borel et al., 1977; Powles et al., 1980). The properties of this metabolite make it an attractive tool in the investigation of the immune response (Parker et al., 1984; Truffa-Bachi, 1987; Girardin, Brossard, 1989).

Recently we have demonstrated (Girardin, Brossard, 1989), that CsA: (1) diminishes the secondary humoral response of rabbits to female I. ricinus bites, (2) blocks the immediate cutaneous reaction (type 1) normally developed by re-infested animals after the intradermal injection of tick salivary gland antigens and (3) impairs the delayed type hypersensitivity reaction (type IV) of the hosts to the same antigen administration.

In the present study, we analysed the effects of treating rabbits with CsA during a 1st or 3rd infestation on the biology of $I$. ricinus ticks. We considered the following parameters: (1) the duration of the bloodmeal; (2): the weight of the engorged females; (3): the duration of preoviposition; (4) the weight of the egg layings; (5): the egg conversion factor; (6): the duration of the embryogenesis; (7): the yield of the parasitic cycle (egg laying and hatching frequencies). 
MATERIAL AND METHODS

\section{Host animals}

Male Himalayan rabbits of genotype $\operatorname{aac}^{\mathrm{H}} \mathrm{c}^{\mathrm{H}}$ were infested 1 or 3 times with 10 male and 10 female $I$. ricinus. Only females of this species engorge, but copulation is necessary for an optimal bloodmeal (Graf, 1978a). A 15 day delay separated the infestation periods. For each infestation, 5 rabbits were treated with CsA. During the 1st infestation, 6 rabbits served as controls and 5 control animals were used for the $3 \mathrm{rd}$ infestation. The hosts were aged from 3 months (1st infestation) to 5 months (3rd infestation) and weighed $2.5 \mathrm{~kg}$ on average.

\section{Ticks}

The $I$. ricinus ticks used in our experiments were reared in our laboratory according to the method of Graf (1978b). During the infestations, the ectoparasites were confined within a cloth bag placed over the ear of the rabbit. A collar prevented the host from grooming. Engorged ticks were taken, weighed and reared.

\section{IMMUNOSUPPRESSIVE TREATMENT}

As described by Lindsey et al. (1980), we dissolved the CsA (Sandoz AG, Basel) in mineral oil (Miglyol 812, dynamit nobel). A daily dose of $25 \mathrm{mg} / \mathrm{kg}$ was administrated to the rabbits subcutaneously. Control animals were subjected to subcutaneous injections of the single solvent $(0.5 \mathrm{ml}$ mineral oil per day). Considering the strength of the immune response (Papatheodorou, 1985; Girardin, 1987) and that the resistance extends the period of tick feeding (Bowessidjaou et al., 1977), we performed the treatment on days -1 to +6 for the 1 st infestation and on days -2 to +8 with the 3 rd infestation.

\section{Statistics}

We used the non parametric Mann-Withney test (Siegel, 1956) for the comparison of the data obtained for each variable, except for the yield of the parasitic cycle. In this case, we analysed our results by means of the frequency exact test (Ostle, 1963).

\section{RESULTS}

Results are summarized in Table I. For each variable, we did « vertical » comparisons of our data (1st infestation versus 3 rd infestation), in order to demonstrate the effects of rabbits resistance on the biology of the ticks, and to determine the influence of CsA on host immunity. A direct effect of CsA on the biology of the ticks was estimated by proceeding to « horizontal » assessment of our results (control versus treated).

\section{1 - Duration of the bloodmeal}

During the 3rd infestation, the $I$. ricinus females remained attached to control hosts for a longer time than during the 1 st $(p<0.01)$. Treatment of the rabbits diminished the duration of the bloodmeal during the 3rd infestation $(p<0.001)$, but increased it during the 1 st $(p<0.01)$.
TABleaU I. - Influence of treating rabbits with CSA during a 1st or a 3rd infestation on the biology of I. ricinus. St-dev: standard deviation. For p values, see text and figures 1, 2 and 3.

\begin{tabular}{|c|c|c|c|c|c|c|}
\hline & \multicolumn{6}{|c|}{ INFESTATION 1} \\
\hline & \multicolumn{3}{|c|}{ CONTROLS } & \multicolumn{3}{|c|}{ TREATED } \\
\hline & Mean & $\underline{\text { St-dev }}$ & $n$ & Mean & $\underline{\text { St-dev }}$ & $\underline{n}$ \\
\hline Durstion of the bloodmeal (hours) & 163.72 & 18.47 & 46 & 177.93 & 19.90 & 45 \\
\hline Weight of the engorged ticks $(\mathrm{mg})$ & 226.62 & 102.76 & 46 & 240.66 & 54.07 & 45 \\
\hline Duration of the preoviposition (days) & 9.67 & 2.00 & 36 & 12.77 & 8.87 & 39 \\
\hline Weight of the egg layings (mg) & 115.28 & 50.40 & 36 & 83.82 & 29.96 & 39 \\
\hline Egg conversion factor & 0.43 & 0.11 & 36 & 0.34 & 0.10 & 39 \\
\hline Duration of the embryogenesis (days) & 36.09 & 7.59 & 35 & 48.45 & 13.69 & 31 \\
\hline Egg laying frequency & & $36 / 46$ & & & $39 / 45$ & \\
\hline Hotching frequency & & $35 / 36$ & & & $31 / 39$ & \\
\hline
\end{tabular}

\begin{tabular}{|c|c|c|c|c|c|c|}
\hline & \multicolumn{6}{|c|}{ INFESTATION 3} \\
\hline & \multicolumn{3}{|c|}{ CONTROLS } & \multicolumn{3}{|c|}{ TREATED } \\
\hline & Mean & $\underline{\text { St-dev }}$ & n & Mean & St-dev & $\underline{n}$ \\
\hline Durotion of the bloodmeal (hours) & 200.86 & 26.58 & 42 & 179.81 & 18.25 & 42 \\
\hline Weight of the engorged ticks (mg) & 188.88 & 88.89 & 42 & 201.13 & 75.93 & 42 \\
\hline Duration of the preoviposition (doys) & 16.07 & 7.11 & 30 & 9.46 & 1.73 & 28 \\
\hline Weight of the egg loyings $(\mathrm{mg})$ & 55.92 & 50.36 & 30 & 80.83 & 33.30 & 28 \\
\hline Egg conversion ractor & 0.31 & 0.16 & 30 & 0.34 & 0.11 & 28 \\
\hline $\begin{array}{l}\text { Durotion of the embryogenesis (days) } \\
\text { Egg laying frequency }\end{array}$ & 64.84 & $\begin{array}{l}8.86 \\
30 / 42\end{array}$ & 19 & 45.78 & $\begin{array}{l}7.50 \\
28 / 42\end{array}$ & 23 \\
\hline Hotching frequency & & $19 / 30$ & & & $23 / 28$ & \\
\hline
\end{tabular}

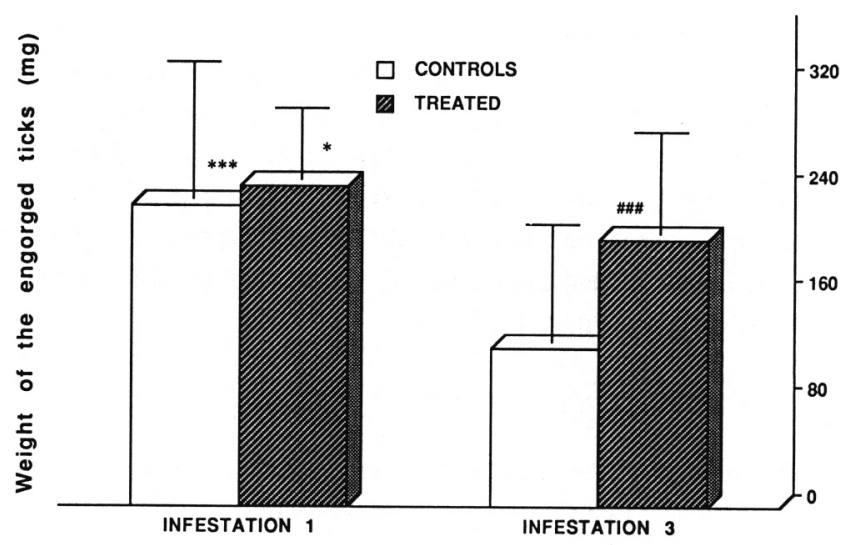

FIG. 1. - Influence of treating rabbits with CsA during a 1st or a 3rd infestation on the engorgement of I. ricinus females. Differences between the infestations: ${ }^{*} p<0.05,{ }^{* * *} p<0.001$. Difference between ticks on control or treated hosts: IIIIII $p<0.001$.

\section{$2-$ Weight of the ticks}

Immune-mediated resistance to tick feeding caused a dramatic decrease in the weight of the engorged ticks (fig. 1). In fact ticks fed both on control and treated rabbits took less blood during the 3rd infestation ( $p<0.001$ for « control » ticks, $p<0.05$ for ectoparasites fed on treated hosts).

However, the feeding of ticks on multi-infested rabbits was favored by the treatment $(p<0.001)$. During the 1 st infestation, the engorgement was only slightly higher in the females on treated hosts.

\section{3 - Duration of the preoviposition}

Ticks fed on control rabbits laid their first eggs later following the 3 rd infestation than after the 1 st $(p<0.001)$. 


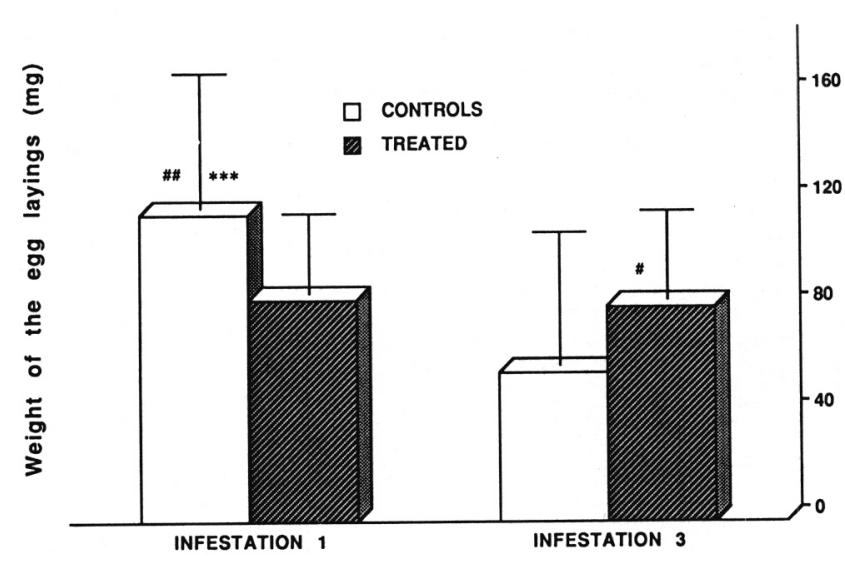

FIG. 2. - Influence of treating rabbits with CsA during a 1st or a 3 rd infestation on the weight of egg layings of $I$. ricinus females. Difference between the infestations: ${ }^{* * *} p<0.001$. Differences between ticks on control or treated hosts: $-p<0.05$, IIIIII $p<0.01$.

However when engorged on treated hosts an opposite effect was observed $(p<0.01)$. CsA clearly impaired expression of the resistance on the preoviposition. In fact, ticks fed on treated rabbits laid their eggs earlier than did those fed on control animals after a 3rd infestation $(p<0.001)$. However, the drug may have directly disturbed the oogenesis, because treatment delayed egg deposition during the 1 st infestation $(p<0.05)$.

\section{$4-$ Weight of the egg layings}

Immune-mediated resistance caused a decrease in the weight of the egg layings from females fed on control rabbits $(p<0.001$, fig. 2$)$. This adverse influence was suppressed by administration of CsA to hosts, since no difference was detected between the egg layings of ticks engorged on treated animals.

We observed opposite effects of CsA treatment during a 1st or a 3rd infestation. The egg layings from females fed on treated hosts were smaller after a 1st infestation $(p<0.01)$ and larger after a 3rd infestation $(p<0.05)$ than those from ticks on control animals, suggesting that CsA may exert an adverse direct action on the mechanisms of egg production.

\section{5 - Egg conversion factor}

With the control ticks, the values recorded in the present study for the egg conversion factor were less than those obtained by Graf (1978a) or Papatheodorou (1985). Nevertheless, this variable decreased dramatically in the course of successive infestations $(p<0.01, f i g .3)$. This difference was abolished by CsA treatment.

The egg conversion factor for females engorged on rabbits treated during a 1st infestation was greatly diminished when compared with that obtained for ticks fed on con-

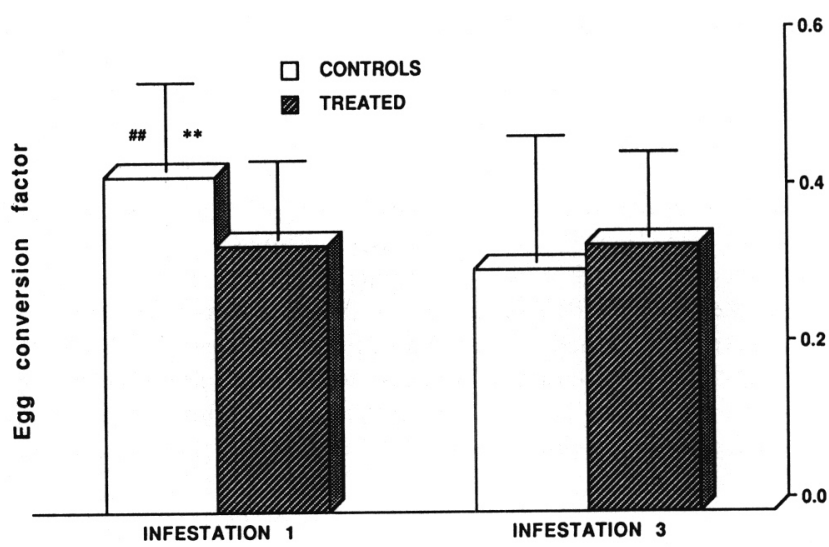

FIG. 3. - Influence of treating rabbits with CsA during a 1st or a 3rd infestation on the egg conversion factor of $I$. ricinus females. Difference between the infestations: ${ }^{* *} p<0.01$. Difference between ticks on control or treated hosts: IIIIII $p<0.01$.

trol hosts $(p<0.01)$. This again confirms the harmful action of CsA on the reproduction mechanisms of the ectoparasites.

\section{Duration of the embryogenesis}

Embryogenesis of eggs laid by females fed on control rabbits was quicker after a 1st than after a 3 rd infestation $(p<0.001)$. The ectoparasites engorged on treated animals during the 1st or the 3rd infestation laid eggs which hatched within the same delay.

After a 3rd infestation, eggs of ticks fed on treated hosts hatched earlier than if engorged on control animals $(p<0.01)$. For the 1 st infestation, we observed the contrary $(p<0.05)$. Thus the drug may also directly disturb embryogenesis.

\section{7 - Egg laying and hatching frequencies}

The resistance acquired by control rabbits only slightly affected the egg laying frequency. On the other hand, we observed a significant decrease of this proportion after a 3rd infestation in the ticks of the treated group $(p<0.05)$. Host immunity to $I$. ricinus had a dramatic action on the hatching frequency: this ratio was lower in control tick of 3rd infestation than those of 1st infestation $(p<0.001)$. The effect was abolished under the influence of the immunosuppressive treatment.

Eggs issued from females after a 1st infestation on treated rabbits hatched in a significantly. lower proportion than those from the control population $(p<0.05)$. This was not the case after a 3rd infestation.

\section{DISCUSSION}

Previous studies demonstrate that the immune response directed against female I. ricinus disrupts many of the feed- 
ing and digestive (Girardin, 1987; Brossard, Papatheodorou, 1990) as well as reproductive (Bowessidjaou et al., 1977; Brossard et al., 1982) mechanisms of these ticks. The resistance phenomenon is obviously detectable during a reinfestation, and markedly amplified during a 3rd infestation. Our results obtained in ticks fed on control rabbits confirm these observations.

Different immunosuppressive treatments allow an attenuation or a blockade of the resistance developed by hosts against ticks. Thus Allen (1973), and then Wikel and Allen (1976) have obtained these effects on guinea pigs resistant to Dermacentor andersoni larvae, using the cytostatic drugs methotrexate and cyclophosphamide, respectively.

In the present study, we treated rabbits with CsA during a 1st or a 3rd infestation with female I. ricinus. This regimen attenuated the effects of the resistance of the hosts against the ectoparasites during the 3rd infestation. Consequently the feeding and preoviposition periods were then reduced, while the bloodmeal and the egg layings were generally more voluminous. Moreover eggs laid by females engorged on hosts treated during a 3rd infestation hatched earlier.

We postulated that the favorable effect of the treatment for the ticks is due essentially to the depression of the immune system of the rabbit by the drug. In a previous study we demonstrated with our system the influence of CsA on the secondary antibody response, as well as on the cutaneous immediate and delayed type hypersensitivity reactions to tick salivary antigens (Girardin, Brossard, 1989). This was roughly a consequence of the effects of the drug on the cellular component of the immune system (chiefly the $\mathrm{T}$ helper cells) described in detail by others (Borel $e t$ al., 1977; Borel, Lafferty, 1983; Thomson et al., 1983a; Thomson et al., 1983b). In another system CsA may also cause perturbations of the development of Schistosoma mansoni through its effects on the immune system of the host (Bueding et al., 1981; Nilsson et al., 1985; Thomson et al., 1986).

However, as we observed, the indirect beneficial effects for ticks provided by the immunosuppressive agent, were partially counterbalanced by an injurious direct action on the tick reproductive success. The later effect was obviously observable during the 1st infestation. Thus, the detachment of ticks from treated rabbits was delayed, leading to a prolonged and greater exposition to the drug, and to the components of the growing host's immune response. Females, when engorged on treated hosts, layed lighter and late egg layings. Furthermore, the average egg conversion factor for females fed on treated rabbits, on the one hand was lower than that recorded for control ticks, on the other hand, was equivalent to that normally observed by ticks engorged on resistant hosts. In addition, CsA caused a dramatic failures in the hatching of eggs. This drug may also exert a direct adverse action against various Plasmodia
(Nickell et al., 1982), rodent filaria and trichina (Borel, Lafferty, 1983).

Acknowledgements. - This work was supported by the Swiss National Foundation for Scientific Research, grant number 3.303.84. The results of this study represent part of a thesis by P. Girardin. We warmly thank Prof. Jean-François Borel (Preclinical Research, Sandoz AG, Basel/Switzerland) for providing us with CsA and for his helpful tips.

\section{RÉFÉRENCES}

Allen J. R. : Tick resistance: basophils in skin reactions of resistant guinea pigs. Int. J. Parasitol., 1973, 3, 195-200.

Borel J.-F., Feurer C., Magnee L., Staehelin H. : Effects of the new anti-lymphocytic peptide cyclosporin A in animals. Immunology, 1977, 32, 1017-1025.

Borel J.-F. : Cyclosporin-A: present experimental status. Transplant. Proc., 1981, 13, 344-348.

Borel J.-F., Lafferty J. : Cyclosporin: speculation about its mechanism of action. Transplant. Proc., 1983, 15, 1881-1885.

Bowessidjaou J., Brossard M., Aeschlimann A. : Effects and duration of resistance acquired by rabbits on feeding and egg laying in Ixodes ricinus L. Experientia, 1977, 33, 548-550.

Britton S., Palacios R. : Cyclosporin A. - Usefulness, risks and mechanism of action. Immunol. Rev., 1982, 65, 5-22.

Brossard M. : Rabbits infested with the adults of Ixodes ricinus L.: Passive transfer of resistance with immune serum. Bull. Soc. Pathol. Exo., 1977, 70, 289-294.

Brossard M., Fivaz V. : Ixodes ricinus L.: mast cells, basophils and eosinophils in the sequence of cellular events in the skin of infested or reinfested rabbits. Parasitology, 1982, 85, 583-592.

Brossard M., Girardin P. : Passive transfer of resistance in rabbits infested with adult Ixodes ricinus L.: Humoral factors influence feeding and egg laying. Experientia, 1979, 35, 1395-1396.

Brossard M., Monneron J. P., Papatheodorou V. : Progressive sensitization of circulating basophils against Ixodes ricinus L. antigens during repeated infestations of rabbits. Parasite Immunol., 1982, 4, 355-361.

Brossard M., Papatheodorou V. : Immunity against female Ixodes ricinus L.: effect on feeding and haemoglobin digestion. Ann. Parasitol. Hum. Comp., 1990, 65, 32-36.

Bueding E., Hawkins J., Cha Y.-N. : Antischistosomial effects of cyclosporin A. Agent Actions, 1981, 11, 380-393.

Girardin P. : Immunité du lapin contre la tique Ixodes ricinus L. (Ixodoidea, Ixodidae): mécanismes effecteurs et leurs effets sur la biologie de l'ectoparasite. Ph. D. Thesis, 1987, Neuchâtel.

Girardin P., Brossard M. : Développement d'une hypersensibilité retardée chez des lapins infestés par les femelles d'Ixodes ricinus L. Ann. Parasitol. Hum. Comp., 1985, 60, 299-309.

Girardin P., Brossard M. : Effects of cyclosporin-A on the humoral immunity to ticks, and on the cutaneous immediate (type I) and delayed (type IV) hypersensitivity reactions to Ixodes ricinus L. salivary gland antigens in re-infested rabbits. Parasitol. Res., 1989, 75, 657-662.

Graf J.-F. : Copulation, nutrition et ponte chez Ixodes ricinus L. (Ixodoidea: Ixodidae). $1^{\text {re }}$ partie. Bull. Soc. Entomol. Suisse, 1978a, 51, 89-97.

Graf J.-F. : Copulation, nutrition et ponte chez Ixodes ricinus L. (Ixodoidea: Ixodidae). $3^{\mathrm{e}}$ partie. Bull. Soc. Entomol. Suisse, $1978 \mathrm{~b}, 51,343-360$. 
Lindsey N. J., Harris K. R., Norman H. B., Smith J. L., Lee H. A., Slapek M. : The effect of cyclosporin A on the primary and secondary immune responses in the rabbit. Transplant. Proc., 1980, 12, 252-255.

Nickell S. P., Scheibel L. W., Cole G. A. : Inhibition by cyclosporin A of rodent malaria in vivo and human malaria in vitro. Infect. Immun., 1982, 37, 1093-1110.

Nilsson L. A., Lindblad R., Olling S., Ouchterlony O. : The effect of cyclosporin A on the course of murine infection by Schistosoma mansoni. Parasite Immunol., 1985, 7, 19-27.

Ostle B. : Statistics in research: basic concepts and techniques for research workers: The Iowa state University Press, 1963, p. 132-133.

Papatheodorou V. : Réaction immunitaire du lapin contre la tique Ixodes ricinus L. (Ixodoidea: Ixodidae) : effets sur la composition et la digestion du repas sanguin. Ph. D. Thesis, 1985, Neuchâtel.

Parker D., Droessler K., Turk J. L. : Kinetics of a single dose of cyclosporin-A on antibody and cell mediated immune response in the guinea pig. Int. J. Immunopharmacol., 1984, 6, 67-74.

Powles R. C., Clink H. M., Hedley D., Bandini G., Watson J. G.,
Lawson D., McElwain T. J., Alexander P. : Cyclosporin A to prevent graft-versus-host disease in man after allogeneic bonemarrow transplantation. Lancet, 1980, $i$, 327-329.

Siegel S. The Mann-Whitney test. In: Non parametric statistics for the behavorial sciences. McGraw-Hill Book Company Inc., Kogagusha Company Ltd, Tokyo, 1956, p. 117-127.

Thomson A. W., Moon D. K., Geczy C. L., Nelson D. S. : Cyclosporin A inhibits lymphokine production but not response of macrophages to lymphokines. Immunology, 1983a, 48, 291-299.

Thomson A. W., Moon D. K., Geczy A. F., Nelson D. S. : Suppression of delayed-type hypersensitivity reactions and lymphokine production by cyclosporin A in the mouse. Exp. Immunol., 1983b, 52, 599-606.

Thomson A. W., Smith S. W. G., Chappell L. H. : Cyclosporin A: Immune suppressant and anti-parasitic agent. Parasitol. Today, 1986, 2, 288-290.

Truffa-Bachi P. : Cyclosporin A: a tool for dissecting the mechanisms of the immune response. Ann. Inst. Pasteur/Immunol., 1987, 138, 644-648.

Wikel S. K., Allen J. R. : Acquired resistance to ticks. II. Effects of cyclosphosphamide on resistance. Immunology, 1976, 30, 479-484. 